\title{
信息化在建筑工程管理中的应用
}

\author{
张亮 ${ }^{1}$ 董玮 ${ }^{2}$ \\ 1 西安宝苑房地产有限公司, 陕西西安 710300 \\ 2 西安华力通市政工程有限公司，陕西西安 710300
}

[摘要]在当前时期, 信息技术的发展速度是较快的, 其在大家的工作、生活中扮演着十分重要的角色, 并使得生活方式有明 显的改变, 大家想要获得所需资源会变得更为简单。从建筑工程角度来说, 将管理工作和信息技术结合起来, 可以使得管理 的实效性大幅提升。

[关键词]信息化; 建筑工程; 管理应用

DOI：10.33142/aem.v2i3.1827 中图分类号: TU71;TU17 文献标识码: A

\section{Application of Information Technology in Construction Management}

\author{
ZHANG Liang ${ }^{1}$, DONG Wei ${ }^{2}$ \\ 1 Xi'an Baoyuan Real Estate Co., Ltd., Xi'an, Shaanxi, 710300, China \\ 2 Xi'an Hualitong Municipal Engineering Co., Ltd., Xi'an, Shaanxi, 710300, China
}

\begin{abstract}
In the current period, the development speed of information technology is relatively fast, which plays a very important role in everyone's work and life, and makes the life style have obvious changes, and it will become easier for everyone to obtain the required resources. From the perspective of construction engineering, the combination of management and information technology can greatly improve the effectiveness of management.
\end{abstract}

Keywords: informatization; construction engineering; management application

引言

在我们国家, 工程管理信息化的应用时间只有 20 年左右, 但信息化水平是较高的。从信息化技术应用的实际情况 来看, 效果是较为理想的。当然, 工程管理呈现出一定的复杂性、长期性, 若想使得企业管理的效果更为理想, 必须 要将信息化管理予以有效落实, 确保每个环节均能够展开有效管理。

1 信息化在建筑工程管理中的应用价值

1.1 提高了整体工作效率

在建筑行业的发展过程中, 建筑工程管理涵盖的内容逐渐向着多样化的方向发展,管理中涵盖的信息内容也在不断 增多, 如进度管理、质量管理、组织及经济管理等, 相应的管理任务和工作量也在加大, 如果管理人员仍采用原有的管理 方式, 势必会影响管理工作的效率和质量, 而信息化的应用, 则可以通过信息平台的建立, 对相关信息进行及时的处理和 优化, 实现无纸化、程序化办公, 大大节省了管理所需的时间, 提高了工作效率和质量。通过信息化的合理利用, 对于实 现工程管理科学化、系统化有着积极作用。

\section{2 实现资源共享, 加强交流效率}

信息化在建筑工程全方位管理中有着较大的促进作用。在工程项目建设中涉及的管理部门相对较多, 为了保证管理 工作的有效落实, 各部门之间需要进行及时有效的沟通和交流, 以便对施工中存在的问题进行完善和调整, 保证工程建 设的顺利进行。通过信息化技术的合理应用, 可以加强部门之间信息交流的速度, 及时掌握工程的进展情况, 实现信息共 享, 第一时间发现施工中存在的问题, 并通过研究制定合理的解决措施, 保证施工的整体进度, 降低成本支出 ${ }^{[1]}$ 。

1.3 优化管理程序, 提高管理水平

信息化的应用为实现工程的精细化管理提供了条件和保障, 实现了对管理流程的重新构建和完善, 对原有的管理模 式进行了变革, 进一步提升了工程管理的质量和水平。同时信息化建设也为管理系统的建立和优化提供了帮助, 保证各 项工作开展的有序性, 提升了企业竞争力, 为企业在激烈市场竞争中的良性发展贡献了力量。

\section{2 建筑工程信息化管理常见问题}

\section{1 区域发展不平衡}

我们国家幅员辽阔, 不同地区的经济水平是有一定差异的, 经济发达地区对人才的吸引力较大, 技术也较为先进, 在理论研究、实践研究方面具有优势, 另外, 政府也会给予企业大力支持, 这样一来, 建筑工程在展开信息化管理时 就能够保证资金、人员满足需要，发展速度自然是较快的 ${ }^{[2]}$ 。 


\section{2 认识程度不足}

建筑工程所要投入的资金很大，因而投入、产出成为了关注的重点。若想使得建筑工程管理的信息化程度大幅提 升, 资金投入是必不可少的, 尤其在对硬件进行改造时，经费投入相对较大，然而在短时间内是无法带来显著受益的， 这就使得不少的企业对此并不关注，有些企业甚至不愿意投入任何资源 ${ }^{[3]}$ 。

\section{3 应用范围较窄}

信息化管理应该要落实到生产、经营的每个环节中, 确保其能够产生综合作用。然而在管理的过程中, 对其产生 影响的因素是比较多的, 在一些建筑企业的意识中, 信息化管理只是工具, 可以在某个环节中产生作用比方说, 可以 在设计、招投标等阶段中予以应用，这样就会使得信息化管理具有的作用难以真正展现出来。

\section{3 加强我国建筑工程管理信息化的措施}

\section{1 加强政策和资金人才}

政府职能部门应该要履行好自身的职责, 制定出行之有效的措施, 确保信息化管理能够得到有效落实。信息化管 理的相关标准要及早出台, 从当前信息化管理的现状出发, 完成编码体系的建设工作。将电子商务规范予以明确, 通 过其对承包商、供应商展开监管, 使得现有的资源能够得到充分利用, 保证工程开发工作能够有序展开。当信息化建 设目标切实达成后, 作业效率会有一定程度提高, 成本也能够控制在合理的范围内, 因此说, 必须要将资金引导做到 位, 将计算机网络技术予以充分利用, 同时要大力培养信息化人才, 管理技术人员的培训工作也要做到位, 另外, 现 有人才必须要合理利用, 确保其能够发挥出自身的才能。在进行工程设计时, 邀请专业人员参与, 将管理、检验等工 作切实做到位。从企业的角度来说, 应该要引入信息化人才, 主动和科研单位展开合作, 这样可以将科研单位已有的 资源、设备予以利用，使得开发时间切实缩短，开发成本也能够大幅降低 ${ }^{[4]}$ 。

\section{2 不断加快同类型、同系列软件的开发效率}

对于建筑企业来说, 若想保证自身的稳健发展, 必须要将发展的方向、目标予以明确, 对软件开发也要重点关注。 在我们国家, 信息化发展的速度是较为缓慢的, 软件开发工作相较于域外先进国家也有一定的距离, 所以说, 如果想 要促使建筑工程信息化管理切实达成, 一定要将先进国家的成熟经验引入进来。在建筑工程信息化发展持续加快之际, 可对计算机技术具有的准确性、便捷性予以利用, 建立起施工模拟图, 这样就能够将施工中可能出现的问题寻找出来, 在第一时间进行纠正, 如此就可保证施工有序展开。

\section{3 搭建多层标准化平台系统}

工程管理涉及的内容是较多的, 模式确定、组织设置、工作流程、信息管理、规章制度等均涵盖在其中, 管理环 节也较为复杂, 除了要完成合同管理、现场施工管理外, 财务管理、材料设备管理等也是不可忽视的。若想使得管理 效果达到预期, 企业则要构建起系统信息平台, 通过其完成现场管理、远程监控、多方协作等工作, 这样一来, 信息 的交换、整合就能够达成。另外, 项目过程也是不可忽视的, 计划进度、资金会计、额定成本、人员管理、分包管理、 变更合计、物资设备等均要做到位, 这样方可保证管理成效更为显著。在对项目信息化系统进行研发时, 以上内容均 要予以考虑, 尤其是在对流程进行再造时, 以及建立数据中心时, 要将部门单一运用予以打破, 确保相关内容能够联 结起来, 如此方可使得相关业务模块真正实现联合健康。除此以外, 对项目部和各方的关系也要进行协调, 确保工作 环境更为理想, 满足信息化管理的实际需要 ${ }^{[5]}$ 。

\section{4 构建起科学完善的信息管理系统}

信息技术的发展速度是较快的, 在此背景下, 信息化和工程管理也实现了融合, 这样就可实现资源共享, 并使得 数据计算更为准确, 工程管理也就会更加的便捷。这里需要指出的是, 如果信息发展过于单一的话, 在工程数量持续 增加时, 信息化、工程管理会出现脱节的问题。为了改变此种情况, 应该要建立更为完善的信息系统, 确保数据能够 实现整合，在展开工程管理时，信息化具有的作用也就能够充分发挥出来。

\section{结语}

综上所述, 信息化水平在逐步发展, 建筑工程管理水平也在逐渐进步, 这两者进行有机的融合形成了现代化的工 程管理。尽管信息化在建筑工程管理当中已经不是一个新的概念, 但在融合发展的过程当中仍然存在着许多的问题, 我们可以通过提升企业管理水平、加强管理类软件的开发、提升相关管理人员的个人能力水平、建科学合理的信息系 统等方式, 来突破传统管理模式的束缚, 不断促进我国建筑工程管理朝着更具科学性、更加现代化的方向发展。

\section{[参考文献]}

[1]周喻.信息化在建筑工程管理中的应用 [J]. 江西建材,2020(01) : 125-126.

[2]秦昊.信息化在海外建筑工程管理中的应用及发展 [J].工程建设与设计, 2020(01) : 183-184.

[3]杜振羽.信息化在建筑工程管理中的应用探究 [J]. 地产, 2019 (23) : 63 .

作者简介: 张亮 (1982-), 男, 陕西西安人, 汉族, 中共党员, 大学本科学历, 助理工程师, 研究方向为建筑工程管理 (房地产开发建设)。董玮(1978-), 男, 陕西西安人, 汉族, 大学专科学历, 助理工程师, 研究方向为市政工程管理。 